\title{
ESBOÇO DE UMA INTERPRETAÇÃO FENOMENOLÓGICA DA IMAGINAÇÃO MATERIAL DE BACHELARD
}

\author{
Joaquim Carlos Araújo
}

\section{\$1. O ser transcendente como cogitatum qua cogitatum.}

A grande novidade filosófica da fenomenologia husserliana, adentro de uma extensa radição que sempre tematizou a teoria do conhecimento, constitui-se na singular distinção entre conteúdo real $^{`}$ (de um acto) imanente da consciência cognoscente e imanência intencional ou conteúdo intencional (de um acto) que qualifica a presença de um objecto à consciência cognoscente. A análise descritiva dos objectos intencionais torna assim possível uma fenomenologia pura ou transcendental ${ }^{2}$. Mas, a consciência psicológica (zona do ser) é, por

10 objectivo da fenomenologia é a descrição da "totalidade integral das vivências parciais" de que um acto realmente se compõe, o que Husserl chama "conteúdo fenomenológico ou real de um acto" - "Unter dem reellen oder phänomenologischen Inhalt eines Aktes verstehen wir den Gesamtinbegriff seiner, gleichgültig ob konkreten oder abstrakt Teile, mit anderen Worten, den Gesamtinbegriff der ihn reell aufbauenden Teilerlebnisse" (Husserl, Logische Untersuchungen, V, (Husserliana XIX / 1), zweiter Band, erster Teil, Den Hague, Martinus Nijhoff, 1984, § 16, p. 411). A metodologia utilizada consiste numa análise psicológica puramente descritiva. Por exemplo, a análise puramente descritiva de um complexo fónico articulado descobre os sons e as partes abstractas ou formas unitárias desses sons; não encontra nada do género das vibrações sonoras, o orgão da audição, etc. Nem ainda, o sentido ideal que faz do complexo fónico um nome por exemplo; e ainda menos a pessoa que pode ser nomeada por esse nome. Conclusão: as vivências intencionais subentendem partes e facetas que são possíveis de distinguir.

2 Haverá, no entanto, que perguntar: como se opera a conversão da atitude psicológica (ciência empírica) para a atitude fenomenológica (ciência ideal)? Levava-nos longe esta questão! Todavia, desejamos dar nota de algumas teses husserlianas. Eis, assim, algumas das regras teorizadas por Husserl: a) excluir apercepções e posições de existência (ciência empírica); b) basear as ideações simplesmente no que é apreendido na experiência interna do ego ou pela intuição interna na simples imaginação (enquanto realidade pura de vivência); c) destacar destas, pela intuição, (ideativamente) essas espécies ideais de vivências que são as essências gerais (e suas relaçōes). Ora, o que está sobretudo em questão é o abandono da perspectiva exclusiva da existência empírica. Pretende-se alcançar evidências puras cuja descrição releve de uma ciência ideal, depurada de toda a posição que implique existência de realidades, depurada de toda a experiência, se bem que, e em última instância, a experiência, considerada de um modo geral, terá sempre de funcionar como campo fenomenológico básico, ou condição de possibilidade, donde podem brotar todos os tipos de vivências. Conclusão: o que é visado em análises deste tipo possui uma validade de essência puramente fenomenológica. Por isso, as posições de existência exercem uma acção ou efeito mínimo nas análises da fenomenologia pura.

Phainomenon, Lisboa, Ediçōes Colibri, 2000, pp. 47-61.

DOI: 10.2478/phainomenon-2000-0002

EC 
isso, posta entre parêntesis ( $\varepsilon \pi \circ \chi \eta)$ para se poder dar atenção à vida da consciência por si, onde a contingência dos entes, a dúvida e a mutabilidade do ser, escapa à (descoberta da) essência da consciência. Descartes foi o grande pedagogo orientador e Husserl ultrapassou o mestre - esta via cartesiana terá sido sistematicamente desenvolvida por Husserl no primeiro volume das Ideen e, pelo menos, até à edição da Krisis em 1936. No entanto, a epoché mais não faz que pôr fora de circuito uma equívoca ideia acerca da consciência e da forma como esta julgava apreender o objecto transcendente. Cria um vazio para dar início a um novo discurso. Constitui-se, com efeito, como atitude teórica que é, mais como uma re-condução do homem a si mesmo do que um simples método de pôr entre parêntesis ${ }^{3}$.

Descobre-se o mundo como o pensado, como o que simplesmente aparece à e se esgota na (pura) consciência do sujeito. Portanto o ser que transcende o sujeito, o mundo, só é como cogitatum qua cogitatum. No âmago da imanência pura o pensado surge tão-só como o correlato de um acto de pensamento (cogito) ou, de outro modo, o noema apenas se compreende como correlato da noese. Toda a espécie de filosofia que pretenda desligar os momentos ideais ou intencionais (caracteres noemáticos) dos momentos reais ou hiléticos (caracteres noéticos) do objecto, torna-se artificial. A qualidade do acto intencional (ou o modo em que o objecto é visado, e de um modo geral, pela percepção, recordação ou imaginação), é inseparável da matéria do acto intencional ${ }^{4}$ (ou o modo do

3 Ou como refere E. Fink (De la phénoménologie, Trad. Francesa de D. Franck, Paris, Ed. de Minuit, 1974, p. 154): "On peut dire en manière de thèse: la reduction phénomonélogique n'est pas primairement une méthode de simple "mise hors circuit", mais de re-condution (Zurïckleitung). Elle conduit le sujet philosophant, dans la prise de conscience de soi la plus radicale, à travers lui-même, vers la vie de croyance transcendental (vie recouverte par son auto-perception en tant qu'homme), dont le monde "est" le corrélat de validité". E mais à frente: "[...] en un mot l'époché phénoménologique n'est rien moins qu'une action intellectuelle sans conséquence, “ purement “ théorique" (p. 180).

${ }^{4} \mathrm{O}$ objectivo de Husserl é também explicar o conteúdo intencional enquanto objecto intencional (cf. Husserl, Logische Untersuchungen, V, § 17). De que se trata esta identificação? Por questões de economia temática, e ultrapassando explicações de circunstância tomemos um exemplo. Quando me represento uma árvore o objecto intencional é precisamente essa árvore. No entanto, há que elaborar uma distinção no que diz respeito ao objecto intencional: a) "o objecto [assim] tal como ele é visado" - "[...] der Gegenstand, sowie er intendiert ist [...]" (Logische Untersuchungen, V, \& 17, p. 414, linha 18) - de acordo com a(s) minha(s) intenção(ções) em causa, ou seja, um objecto é sempre representado de tal ou tal modo, podendo ser, eventualmente, o centro onde convergem variadas intenções (judicativas, optativas, afectivas, imaginativas, etc.); b) "o objecto [o qual] que é visado" - "[...] der Gegenstand, welcher intendiert ist [...]" (id. ibid. linha 19) - por si, independentemente da(s) intenção(ões), ou seja, podem alcançar-se múltiplas representações, pretendendo, no entanto, todas elas (em razão da unidade objectiva do acto do conhecer) representar o mesmo objecto. Conclusão: independentemente da multiplicidade possível de representações, "em todas elas o objecto visado [ou representado] é o mesmo mas, em cada uma delas, a intenção é diferente" - "In ihnen allen ist dann der Gegenstand, welcher intendiert ist, derselbe, aber in jeder ist die Intention eine verschiedene, jede meint den Gegenstand in anderer Weise" (Logische Untersuchungen, V, p. 414). Qualquer dos modos, em todos os casos que seja visado o objecto intencional, devemos evitar a ambigui- 
próprio objecto visado enquanto que percepcionado, recordado ou imaginado) o que Heidegger conceptualizará como Als Struktur (a estrutura enquanto que): o objecto apenas pode ser visado enquanto tal (ou tal). Por exemplo, afigura-se absurdo querer recordar algo (qualidade) independentemente desse algo ter sido de facto vivido (matéria). Obviamente que não me é permitido recordar ou percepcionar o vacuum ou o plenum do universo; a existência do(s) deus(es); a morte do meu ser. Por paráfrase de Kant, digamos que a consciência encontra os seus limites à custa da reflexão sobre (in)evitáveis paralogismos e outros raciocínios dialécticos que ela mesma produz. Não obstante, é-me permitido imaginá-los! Neste caso, por meio da livre fantasia ou simples imaginação, no sentido estrito dos termos. Em qualquer dos modos, só por referência a um mundo já vivido é possível ao ego imaginar o que quer que seja.

É pela via da redução fenomenológica, com os seus diversos momentos, que se evita por um lado a ambiguidade judicativa da relação eu-mundo e, por outro, se ganha o sentido noemático pertencente a cada vivência. Por exemplo, na recordação, ou na imaginação, depois de renovadas pela redução, apenas se detém o recordado ou o imaginado como tal. Que não se entenda, no entanto, a redução fenomenológica enquanto uma subtracção ou privação de algo que existe de facto - o que, de resto, não faria qualquer sentido - mas como indecisão, suspensão do juízo, ou melhor, neutralização. A fenomenologia, a limite, mais não é que a simples explicitação de uma situação no mundo. A reflexão sobre o próprio fenómeno pressupõe já o fenómeno, este não tem interior nem exterior. O fenómeno não está para além do seu aparecer, daí que nos ofereça o aparecer e o ser 'simultaneamente, ou seja, o fenómeno esgota-se totalmente no seu aparecer, numa evidência apriorística portanto. É este, aliás, um bom exemplo da perspectiva fenomenológica dinâmica de Bachelard que, como veremos, parte fundamentalmente da tese da imagem pela imagem - ou, como lembra Octavio Paz "o sentido da imagem é a imagem mesma"s. A bem dizer, a imagem constitui-se, por si só, numa gratuitidade radical, quase como um súbito trejeito do espírito - ideia estabelecida por Bachelard, já em Lautréamont.

A fenomenologia está antes ou é anterior e independente de qualquer ciência ou metafísica (neste caso, a qualquer metafísica da imagem) - por isso Bachelard a preferiu à psicologia, por exemplo. Melhor, no nosso ponto de vista ele adoptou, primeiramente, e plagiando o professor João Paisana, essa atitude que não depende de qualquer tomada de posição sobre a realidade, ou seja, e no caso vertente, descrever a existência efectiva da imagem tal como ela surge

dade, e não falar de conteúdo intencional mas sim de objecto intencional do acto em causa. Até porque, a objectualidade (Gegenstandlichkeit) - isto é, o momento da síntese intuitiva - sobre a qual se dirige um acto, tomado na sua totalidade - "Akt voll und ganz genommen" - (acto total), ou na sua parcialidade (acto parcial) - "Teilakte" - é sempre, e só, uma.

${ }^{5} \mathrm{Cf}$. Aquien, Michèle, Dictionnaire de poétique, Les Usuels de Poche, Librairie Générale Française, 1993, p. 158. 
pura ao emergir no próprio acto intencional em que é visada, a saber, numa total ausência de pressupostos 6 : a ideia da imagem pela imagem ${ }^{7}$. É isto que permitirá investigar a fórmula que adopta uma básica condição de possibilidade para a actividade (dinâmica) do fenomenólogo da imaginação. Diria Novalis, a ima-

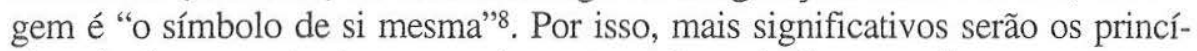
pios da fenomenologia, nomeadamente o da redução, ou seja, para o nosso autor a imagem vale por si só, enquanto vivência dada momentaneamente à consciência ${ }^{9}$.

Mas a realidade natural transcende o seu mero aparecer a uma consciência. Não se fica pelo dado da simples presença-mesma (selbstanwesenheit), em carne-e-osso. Nela são ao mesmo tempo co-dados, ao ego transcendental, ao ego referido a um objecto, todos os aspectos ou partes do fenómeno. Na verdade, todo o objecto é mais visado do que dado. Eu viso, simultaneamente, como um todo, o horizonte, a planície, a montanha, a árvore, esta pedra, etc., na sua totalidade imediata, mas apenas um destes entes preenche, realmente, a minha intenção significativa, apenas um se dá, no momento, numa singular síntese de preenchimento da minha atenção. $\mathrm{O}$ visado pode, pois, estar no sujeito enquanto percepção directa de uma imagem-coisa $(\text { Bild })^{10}$ - estou, agora, a olhar para esta pedra e não para o chão que a recorta e circunda. Pode, de igual modo, dar-se enquanto acto de memória - a pedra que peguei ontem, durante o meu passeio pela praia. Ora, na imaginação, o visado está no sujeito em imagem - represento-me uma pedra de barro azul que não existe.

Assim a imaginação se constitui como atitude específica da consciência em relação à simples percepção. A imagem não se apresenta como um substituto directo da percepção, pelo contrário, ela possui um estatuto próprio, o da

6 Cf. Paisana, J., Fenomenologia e Hermenêutica, Lisboa, Presença, 1992, p. 65.

7 'Il faut rendre a l'image son psychisme primitif. L'image pour l'image, telle est la formule de l'imagination active. C'est par cette activité de l'image que le psychisme humain reçoit la causalité du futur, en une sorte de finalité immédiate." (Bachelard, L'Air et les Songes. Essai sur l'imagination de le mouvement, Paris, Librairie José Corti, 1943, p. 193).

8 "Bild - nicht Allegorie, nicht Symbol eines Fremden: Symbol von sich selbst" (Novalis, Fragmentos, (ed. bilingue), Lisboa, Assírio e Alvim, 1992, p. 49).

${ }^{9}$ Como sabemos, a redução fenomenológica não subtrai ou priva a existência daquilo que é de facto, de modo inverso, ela apenas sugere a neutralização de um modo de ser no mundo; ela apenas se assume como a condição necessária a uma explicitação de uma situação no mundo, o que nos indica o fenómeno dentro dos limites do seu aparecer.

$10 \mathrm{O}$ vocábulo bild, por si só, é equivalente do latim forma, figura ou forma. A imaginação (imagination) enquanto einbildung tem um sentido mais passivo do que recriativo. Este último sentido é reservado para a fiktion. No entanto, a riqueza da língua alemã, deixa ainda revelar a ideia mais geral de uma potência de formar uma imagem, como os românticos entenderam a imaginação, Einbildungskraft, ou ainda, um poder interior mais forte, mais criativo portanto, imaginação como Hineinbildungskraft. À semelhança do universo semântico da língua grega, que distinguia eikazein (representar-se algo em imagem - eikôn -) de phantazein (mostrar em aparência), também os alemães, com o peso da tradição, diferenciaram uma função (meramente) representativa e uma função inventiva (de falsidade) da imaginação. 
imagem pela imagem, quer dizer, é interpretada como um dado no seu puro aparecimento imediato a uma consciência dirigida para a sua materialidade inerente. Ela é espontaneidade pura, ou, por paráfrase se Sartre, só existe na medida em que é transparente para si mesma ${ }^{11}$.

Daí, a percepção empírica da imagem se constituir por assim dizer numa antecipação consciencial. Decidida a imaginar - depois da escolha que fixa o sentido ou "unidade de paisagem" - a consciência adianta-se à realidade recebendo-a na sua actualidade fenoménica, a que serve os seus interesses egológicos momentâneos. "As coisas, refere o autor, aparecem em primeiro lugar onde as esperamos, não as colocamos, lentamente, senão onde elas estão. Se por razões gerais e variadas, o espírito se engana na antecipação da distância, aí terá um erro na fixação mas não necessariamente na solidez desta fixação. Todos os dados retinianos podem, efectivamente, condensar-se à volta do ponto imaginário primitivo, o que prova que a imagem enquanto conjunto é uma construção do espírito e que a imaginação facilmente supre as insuficiências da percepção"12. As imagens previnem-se das coisas! O nó primordial da representação releva menos do impulso exterior, do que dos hábitos ou das condições psicológicas a priori. Mais, antes de ser um ponto específico do real, a representação já foi um "ponto imaginário" do mundo do devaneio ${ }^{13}$.

Acrescente-se que ela, a imaginação, pode constituir-se como uma vivência particular e também como uma modificação universal aplicada a todos os vividos, ou, no caso que mais nos interessa, aplicável a todas as representações bachelardianas da matéria e do seu necessário e consequente dinamismo psicológico, isto é, aquilo a que Bachelard chamou as imagens psicotrópicas ${ }^{14}$.

11 Cf. Sartre, L'imagination, Paris, PUF, 1981, p. 126.

12 'Les choses apparaissent d'abord où on les guette, on ne les place que lentement où elles sont. $\mathrm{Si}$, pour des raisons générales et variées, l'esprit se trompe dans l'anticipation de la distance, il y aura une erreur dans la fixation mais pas nécessairement dans la solidité de cette fixation. Toutes les données rétiniennes pourront fort bien se condenser autour du point imaginaire primitif, ce qui prouve que l'image en tant qu'ensemble est une construction de l'esprit et que l'imagination supplée facilement aux insuffisances de la perception" (Bachelard, Études, recueil posthume de cinq textes présentés par G. Canguilhem, Paris, PUF, 1972, p. 33).

13 "On ne peut mieux prouver que le germe de la représentation (le point de fixation) ne relève nullement de l'excitant, mais bien des habitudes et des conditions psychologiques. Le germe de la représentation, avant de devenir un point précis, avant de se rapprocher du point réel, a été un point imaginaire situé au centre d'une rêverie ou d'un souvenir" (id. ibid. p. 33).

$14 \mathrm{O}$ que no nosso ponto de vista sugere um dinamismo, ou uma por assim dizer orientação das próprias substâncias elementares que, enquanto estímulos materiais, provocam uma resposta física e psicológica no homem, de modo breve, e seguindo a ironia do autor, um "factor de adversidade" das coisas - que, enquanto campo de obstáculos, agridem o ego desperto da consciência imaginativa. A expressão - talvez recriada a partir da significação que a Biologia, ou a Botânica, lhe conferiram - é utilizada tardiamente, só em 1960, aquando da edição de La Poétique de la Rêverie - Paris, 3. ${ }^{\text {a }}$ Ed. Quadrige/PUF, 1989 (v. g. pp. 136; 147; passim) - e tem o sentido de excitação psíquica provocada pelas substâncias, ou de droga imaginária - como o ópio de E. A. Poe - enfim, de um onirismo desperto e vertical. No entanto, a ideia da formação 


\section{§ 2. A imaginação como unidade de presentificação/ /neutralização e a questão da consciência estética.}

A partir da sua especificidade intencional, característica de outras vivências da consciência, a temática da imaginação tomou um novo rumo com Husserl. A imaginação é uma modificação da percepção transcendente, é uma presentificação. Toda a espécie de imaginação possui uma forma característica de apreender os objectos: a presentificação (Vergegenwärtigung). Assim, e enquanto vivência particular, a imaginação é presentificação neutralizada do objecto de um acto perceptivo anterior. Enquanto modificação universal, aplica-se a todos os actos da consciência.

Recuperando o sentido próprio de neutralização, ou seja, privar de validade, não decidir, pensar sem tomar partido, diremos que o fluxo egológico das vivências pode ser constantemente alterado pela neutralidade, quer dizer, pela modificação de neutralidade (neutralitätsmodifikation) enquanto possibilidade constante relativa a todos os modos da consciência. A consciência de imagem (presentificação por representante físico), as disposições, os sentimentos, as paixões da alma, todas as modalidades dóxicas de um modo geral são, igualmente, afectadas pela modificação de neutralidade. A plurivocidade desta expressão em Husserl, afecta a clareza, brevidade e o distinto modo da sua definição. Não obstante, como refere Fink, interpretemos essencialmente a modificação de neutralidade como "uma modificação específica da crença na experiência: uma crença sob o modo do como-se [als ob]"15. Ela, enquanto constituição de aparência (como-se), é um modo primário de ser do ego puro e depende da liberdade deste último para existir segundo uma inautenticidade das suas produções constitutivas, se quisermos, segundo uma constituição neutra ou de aparência, de engano, ilusão - quando a consciência (neutra) retém o visado sob o modo do como-se neutro ${ }^{16}$, do quasi. É errado, no entanto, identificar, de ânimo leve, imaginação e neutralização. Apreender um objecto sensível enquanto imagem supõe também uma consciência imaginante (se bem que de um tipo outro). Com efeito, a presentificação (que pode ser ou não posicional) é o processo fundamental de toda a consciência imaginante (eingebildeter). Mas no caso de esta ser neutra temos aberta a via para outra espécie de modificação imaginativa, a neutralização ou consciência estética - que de resto, Husserl pouco explorou.

de imagens imaginárias a partir da relação primeira da consciência com uma matéria-estímulo, perpassa ao longo de todas as obras de Bachelard, a saber, uma crítica à fraqueza da vontade de imaginar activamente, a apologia de uma espécie de antipsicastenia dos devaneios de imagens (veja-se, por exemplo, Gaston Bachelard, L'Air et les Songes, p. 170).

15 "La modification de neutralité désigne alors une modification spécifique de la croyance en l'expérience: une croyance sur le mode du comme-si"' (Fink, ob. cit. p. 84).

16 Como-se neutro neste caso, pois também se considera um como-se conforme à modificação de re-presentação (cf. Fink, ob. cit. p. 84). Contudo, e de um modo geral, o como-se é "o único carácter descritivo fundamental de todas as representações" (Fink, ob. cit p. 70). 
Numa exposição de arte, se quisermos - e por relação à temática bachelardiana da representação estética - percepciono determinada gravura em cobre que me prende a atenção: a gravura de um cavaleiro num torneio medieval e o que, por exemplo, me faz interrogar de que época seria. Assim, a gravura é presentificada, num acto dóxico ou posicional de interrogação, à minha consciência. Nesta, aparece por abstracção uma figura-imagem, um objecto intencional que reproduz ou que se parece com a figura-coisa-consciência de imagem por representação física. Ora, a certa altura, depois de me aproximar e de a observar com um pouco mais de atenção, a minha imaginação, a liberdade radical do meu ego, solicita o meu pensamento (juízos) para um outro modo de ser da minha consciência e, por gozo estético, esqueço esse mundo das realidades onde me encontro (na sala de um Museu de Arte Antiga). Apesar de o meu modo de apreensão ser o mesmo (pois continuo a ver o cavaleiro e tudo o que envolve a sua imponente figura), já o não é a minha relação psicológica com o modo de existência dessa gravura enquanto imagem mental ou objecto intencional na minha mente: limito-me a um mais restrito entendimento ou compreensão do sentido que a gravura me comunica. Quer dizer, já neutralizei (ou deixei de tomar posição perante) esse acto primeiro de percepção, e fiz, talvez sem o querer, com que ele perdesse a força do real, tornou-se irreal. Pela neutralização, a gravura como volume, em cobre, etc., por assim dizer desapareceu, para ser substituída pela obra de arte. A minha consciência está, de momento, preenchida com uma outra modalidade dóxica de relação à existência desse objecto intencional, ou seja, o acto de crença foi anulado e surgiu uma simples presentificação imaginante sem carácter posicional. Eu sei que o cavaleiro não está ali mas imagino-o, sinto-o etc., como-se estivesse. No entanto, se essa presentificação é novamente neutralizada (por exemplo, se não penso sequer o cavaleiro como existente ou não existente) então, experiencio um outro grau fenomenológico de neutralização. Basta-me a obra de arte como simples aparência, recortada da esfera ontológica, sem relação alguma à realidade que ela representa. Seria esta, no dizer de Manuela Saraiva, a atitude puramente estética que, não se reduzindo a um ou outro grau de imaginação, abriria as portas à irrealidade peculiar do universo artístico, a uma (nova) percepção artística ${ }^{17}$.

17 "Parece-nos portanto que as realidades presentificadas irrealmente coincidem exactamente com as manchas de cor ou os traços a carvão que lhe servem por assim dizer, de corpo irreal. A obra de arte, perdida como realidade mundana, faria apelo, neste caso, não à imaginação presentificante, mas a uma espécie nova de percepção, a percepção artística”, (Maria Manuela Saraiva, "O primado da percepção e a concepção da obra de arte em Husserl", in Revista da Universidade de Coimbra, 1965, p. 85). Partindo da análise de uma "primeira época" de textos originais de Husserl, fase que culmina com a edição do primeiro volume das Ideen (1913), descobre a autora uma "ambiguidade fundamental" do pensamento husserliano sobre tal matéria (e que canoniza o ideal platónico de mimesis da arte realista já em declínio nessa altura): identificação da atitude do artista a uma simples presentificação posicional. No entanto, englobando a fase compreendida entre Ideen II e Formal und Transzendental Logik (no fim da vida do filósofo), conclui, por outro lado, o "abandono" da noção de presentificação e o apelo à modificação de 
Uma primeira conclusão: o acto de imaginação é sempre presentificativo mas nem sempre é neutralizante. Quando se neutraliza o carácter da crença (Glaube) - esse "carácter fundamental da intencionalidade", como refere Husserl ${ }^{18}$ - surge a imaginação livre - tratando-se ainda da mesma matéria intencional. Compreende-se portanto a familiaridade existente entre imaginação livre (fantasia) e consciência estética. A neutralização imaginante faz com que o sujeito aceda à dinâmica da função estética, ao jogo ou movimento constante entre o real e o irreal, entre o que existe perante a minha percepção e o que eu imagino mediante a minha liberdade de fantasiar - que em última instância é sempre e de algum modo referida à primeira. $\mathrm{O}$ mesmo acontece com a consciência simbólica. De facto, para o autor das Logische Untersuchungen tanto a obra romanesca, a literatura de ficção, como as artes plásticas de um modo geral, são unificadas por este tipo de neutralização ${ }^{19}$.

Ao universo noético auto-presentativo do artista, do escritor, do poeta, corresponde a presentificação neutralizada. Trata-se da imaginação livre e da consciência estética e não de presentificações posicionais, como sejam a recordação ou a consciência de retrato (uma forma de consciência de imagem: consciência de imagem por representação física). No entanto, existe um (difícil) ponto essencial comum à recordação e à livre imagem, é, precisamente, a aparição (ou imagem) intuitiva imaginante (Phantasieersheinung). De outro modo, tanto à imagem-memorial (posicional) da recordação como à simples-imagem (não-posicional) da imaginação, corresponde uma presentificação, a saber, no caso da recordação, uma presentificação posicional; no caso do acto de imaginação, a contra-partida dessa modalidade dóxica ou presentificação neutralizada. Assim, e à semelhança da consciência imaginativa, enquanto imaginação livre e desperta pela neutralização da sua recordação base, mostra-se também que a recordação possui algo de fenómeno imaginário ${ }^{20}$.

neutralidade para interpretar o que o próprio Husserl (já) chamava, em Ideen I, o "estético puro" (ob. cit. p. 104, passim). Não compete aqui discutir o valor desta ou daquela espécie de arte, daquela outra corrente, mais abstracta ou não, independentemente dos seus valores sócio-políticos, etc. Aceitemos o pressuposto de que a arte vale por si, mostra-se por si mesma, enquanto objecto intramundano: "A obra de arte é manifestação, epifania. Só distanciando-nos do mundo em que faz irrupção, mas de que não tira a sua origem, a podemos entender na sua essência própria", (ibid. p. 106). Temos para nós que o uso deste conceito de epipháneia, "acto de se mostrar" - careceria de uma melhor explicitação por parte da autora.

18 Citado em Maria Manuela Saraiva, L'imagination selon Husserl, Martinus Nijhoff, La Haye, 1970, p. 180.

19 Cf. Saraiva, L'imagination selon Husserl, p. 209. Por outro lado, foi, com efeito, precisamente neste campo temático, a literatura, que Bachelard iniciou a sua fenomenologia (que apelidamos de) dinâmica do imaginário.

20 Cf. Saraiva, ob. cit. Cap. IV, Introdução e § 4. Nomeadamente: a) "Dans le domaine des auto-présentifications, la présentification positionnelle est le souvenir que l'ont peut aussi désigner par image mémorielle ou par image positionnelle. L'imagination libre proprement dite [a imaginação livre, assim como a consciência de imagem e a recordação, são distinções apon- 
Segunda conclusão: para compreender a imaginação há que articular presentificação e neutralização. Não se afigura suficiente interpretá-las como (apenas) dois processos justapostos. Para a compreender, torna-se necessário analisá-las enquanto unidade conjunta. A imaginação é, portanto, uma modificação de neutralidade ou significação universal susceptível de se aplicar a todas as vivências ou actos da consciência ${ }^{21}$. A imaginação tem que ser analisada enquanto modificação representativa (presentificação) e enquanto modificação qualitativa (neutralização ou modificação de neutralidade). Nas palavras de Fink: "A imaginação é, antes de mais, uma modificação universal de toda a vida da experiência"22. Ou seja, a imaginação é sempre fundada.

Do acima exposto, temos para nós, que a imagem do devaneio se constitui pela sua pretensão a acto posicional, ou seja, um acto de consciência que põe para si mesmo um objecto como(-se) posição existente no espaço das imagens materiais. A "crença como-se", que é o carácter geral da "modificação quasi-posicional", pode definir bem a imagem material bachelardiana ${ }^{23}$. Este espaço da imagem material é o espaço de um tropismo que salta da matéria, e que

tadas pela autora, dentro da consciência imaginante] surgit par la neutralisation du souvenir qui lui sert de base" (p. 176); b) "Le noyau commun au souvenir et à l'image libre est une image dans le sens d'une apparition intuitive imageante, d'une Phantasieerscheinung" (p. 213).

21 Certamente que semelhante temática implicaria uma reflexão mais cuidada sobre a doutrina fenomenológica da redução transcendental. Seríamos, com efeito, levados a pensar que o campo da redução transcendental teria, ela mesma, uma zona de aplicação tão vasta como a própria imaginação. Não faremos semelhante investigação, pois transcende o nosso propósito momentâneo. Acerca deste tema apenas uma nota: a modificação de neutralidade admite um papel fundamental na fenomenologia científica através da epoché universal. A saber, para que se possa descrever, como é intenção da fenomenologia, a relação noético-noemática da pura consciência com o mundo-fenómeno (o seu correlato noemático), a fenomenologia tem de se limitar a receber o dado, ou seja, tem de se assumir como consciência neutra. É esta a perspectiva que nos interessa. Não obstante, é necessário mostrar o carácter platonizante da teoria das essências deste filósofo. Um estudo interessante, e para nós suficientemente representativo desta questão, é o curso dado por Edmund Husserl no semestre de verão de 1925 na Universidade de Freiburg, acerca de psicologia fenomenológica ou intencional (obra editada postumamente, por Walter Biemel, em 1962 - Phänomenologische Psychologie - e retrovertida para a língua inglesa por John Scanlon em 1977, na editora oficial das obras de Husserl). A dada altura, o filósofo apresenta-nos a variação eidética como método de diferenciação do binómio factual (Faktisch) / fantasia (Phantasie), concluindo acerca da permanência e invariabilidade da ideia (eídos). Por exemplo, oiço, de facto, um tom ou opto por fantasiá-lo. Mas o tom, "tomado universalmente", a eídos, mantém-se através da mente, nessas "variações opcionais" e, no caso vertente, "comummente necessárias": "Z. B. verfahren wir so im Ausgang von einem Ton, mögen wir ihn nun wirklich hören oder als Ton " in der Phantasie vorschweben " haben, so gewinnen wir daran das im Wandel " beliebiger "Varienten erfasste Eidos Ton als das hier notwendig Gemeinsame” (Phänomenologische Psychologie. Vorlesungen Sommersemester 1925. Herausgegeben von W. Biemel. (Husserliana IX), zweite Auflag, Den Hague, Martinus Nijhoff, 1962, §9 a), p. 73).

22 Fink, ob. cit. p. 36.

23 Uma expressão de Husserl: "die quasi-positionalen Abwandlungen" (Phänomenologische Psychologie, § 40, p. 204, linhas 8-9). 
influencia o sujeito previamente disposto para este tipo de fenómenos da consciência imaginativa - sendo através desta que o sujeito produz uma obra. Ambicioso desejo de redescoberta das coisas na sua dinâmica natural própria! Por outro lado, este imperativo do imaginário, chamemos-lhe assim, apenas se completa mediante essa consciência que se deve tematizar a si mesma, caso o seu desejo seja a compreensão do fenómeno racional do devaneio diurno. E tomemos a liberdade de apelidar esta consciência como consciência tética de si mesma, quer dizer, de uma auto-consciência que ao descobrir-se através de actos (neutros) de imaginação (a contra-partida dos actos posicionais), revela, desta sorte, a liberdade das suas modalidades dóxicas específicas (dúvida, interrogação, hipótese, desejo, etc.). Pela existência neutralizada dos seus actos, a consciência possui o mesmo objecto tematicamente, não o possuindo, por contra, enquanto realidade ou posição. E se esta liberdade própria do imaginar, se deixasse, em alguma circunstância, exprimir numa "conduta irreflectida", negaria então o seu necessário carácter de ser posicionalmente consciente da sua transcendência. O mundo seria apenas, mais uma potencial qualidade das coisas nunca efectivada. O primum movens do devaneio dissipar-se-ia, por entre os resíduos inconscientes (ou melhor, não tematizados). Assistiríamos à trágica ausência do sonhador da matéria!

É por esta via reflexiva, espontânea, que pensamos distinguir a função temática da imaginação (que examina o seu próprio acto material) da função posicional da imaginação (que sabe da insuficiência existencial directa do seu acto material). A diferença possui, para nós, um sentido operativo, a saber, autoriza o sujeito do devaneio activo a considerar-se um vigilante do seu eu sonhador, a admitir uma "vigilância intelectual de si". A intenção material que o ego dirige às substâncias fica, desse modo, por um lado julgada, enquanto pura imagem que vale por si mesma sem recorrências a outros singulares (teses) e, por outro, consciente do seu limite existencial. A consciência imaginativa toma, então, consciência de si mesma enquanto existente numa situação concreta, aquela que trabalha a imagem conferindo-lhe um sentido criado pela expressão literária - destacando-se, desta feita, da "consciência imagetizante" analisada por Sartre ${ }^{24}$. E para que a imaginação, material e poética, seja enten-

24 Cf. Sartre, L'Imaginaire. Psychologie phénoménologique de l'imagination, Paris, Gallimard, Col. folio essais, 1968, p. 346 e ss. Esta concepção da imaginação como "consciência imagetizante" (conscience imageante), enquanto faculdade que deforma as imagens na sua relação ao acto perceptivo, deriva do que Sartre chamou "postulado de imanência". Percepcionar uma cadeira ou imaginá-la identifica-se, na consciência, como o mesmo objecto em ferro e/ou madeira (se for, obviamente, esse o caso). A consciência não é, pois, o lugar real ou o amontoado de simulacros. Todavia, no acto imaginativo, e porque a consciência afecta o objecto com uma função de irrealidade, ou seja, afirma um nada como seu correlato, diz-se que a cadeira é posta como irreal. Resta-nos acrescentar, que esta concepção sartreana, pretende explicar apenas as deficiências ou a pobreza da imaginação reprodutora, contrariamente ao desvelamento mais rico que, progressivamente, se revela no acto da percep̧̧ão, e por isso difere da imaginação criativa de Bachelard. 
dida enquanto reflexão espontânea, não é suficiente, explica Dufrenne, que ela se mostre (apenas) "consciente de si, como também o é todo o acto de consciência". Mais do que isso, torna-se evidente a necessidade que o cogito a possa "governar e reconhecer-se nela". Tal compromisso, torna a imaginação Bachelardiana não num perigo de alienação mas, e porque ela é sempre "falada", numa inofensiva criação do espírito ${ }^{25}$.

\section{§ 3. Irrealidade do mundo da imagem e fenómeno da imagem.}

O mundo da imagem é a irrealidade presentificada na imagem. Ele é determinado, de modo unívoco, pela sua unidade de consciência intuitiva, pela sua intuitividade do objecto. Na unidade intuitiva da objectualidade (Gegenständlichkeit) existem, no acto intuitivo total, partes preenchidas (partes ou facetas dos objectos que caem actualmente na intuição) e remanescem partes vazias (partes ou facetas dos objectos dadas de maneira inautêntica). Assim é, tanto para a imaginação como para a percepção ou para a recordação.

Sempre há algo que escapa à minha unidade intuitiva actualizada. No caso da recordação, o que escapa, as partes não preenchidas, serão as retenções (o ter-sido) e as protenções (o ter-que-ser) não intuitivas(os). Para a percepção, as partes dadas de modo indirecto ou inautêntico. Na imaginação, as formas neutralizadas, irreais. A irrealidade do mundo da imagem é um momento abstracto da realidade total da imagem, isto é, do mundo da imagem e do suporte da imagem. A imagem, por si, como refere Fink, é a unidade mediadora (mediumbildende) entre os dois ${ }^{26}$. Por exemplo, a imagem representada através de uma escultura de Moore constitui-se como medium entre o mundo da imagem e o seu suporte material - o suporte decide já acerca do modo de ser da própria imagem (ou se quisermos, ainda, do seu modo em que e enquanto que).

No mundo da aparência da arte, da imaginação reprodutiva (consciência de imagem ou de retrato), a percepção da imagem é uma experiência que se constitui ela mesma como o lugar original de uma irrealidade, de um fictum portanto. A imagem - nota Fink - "enquanto conjunto unitário e indissolúvel é um correlato perceptivo"27. Assim se compreende o carácter próprio da imagem, o de ser uma abertura (sichöffnen), janela ou mediatização para o mundo da ima-

25 "Pour que l'imagination soit spontanément réfléchie, il ne suffit pas qu'elle soit consciente de soi, comme l'est aussi bien tout acte de conscience. Il faut qu'elle soit assez docile au cogito qui l'anime pour que ce cogito puisse la gouverner et se reconnaître en elle. Libre à lui de se laisser compromettre par elle: elle ne le compromettra pas. L'imagination pour Bachelard n'est en effet jamais exigeante, jamais aliénante; si profonde qu'elle soit, elle reste inoffensive, parce qu'elle est parlée" (Dufrenne, M.,"Gaston Bachelard et la poésie de l'imagination", in Les Études Philosophiques, 4, 1963, p. 403).

26 Cf. Fink, ob. cit. p. 90, passim.

27 “[...] l'image en tant qu'ensemble unitaire et indissoluble est un corrélat perceptif' (Fink, $o b$. cit. p. 90). 
gem. Pela análise da constituição da imagem, percebemos que esta metáfora, a da janela (ou da janelidade da imagem), com as suas partes reais e irreais, é, de modo preciso, o correlato noemático de um acto medial, da consciência de imagem de um modo geral ${ }^{28}$.

Pelos trabalhos da escola husserliana por nós referidos, da imaginação não foi desenvolvido o seu efectivo papel de criação, a sua autonomia própria. Pois, se bem que, e em última instância, toda a espécie de imaginação é subsidiária da posição de existência de um objecto material, isso não impede, pela nossa leitura de Bachelard, que ela seja mais que isso. Na verdade, a consciência imaginativa, na sua versão de devaneio, apenas postula como thesis para si mesma (para tomar o significado grego do termo) esse simples acto de colocar uma imagem à consciência. É um acto temático, ainda que, como é óbvio, com horizontes não tematizados. Quer isto dizer que ela, a imaginação produtiva, apesar de se obrigar a uma contextualização empírica, não obedece tão somente a essa zona gnoseológica, se bem que dela tire todo o seu conteúdo intencional: os dados sensoriais - diríamos, em linguagem bachelardiana, os dados materiais. Pois, destes, posteriormente, será feita a livre elaboração que convenha ao momentâneo interesse do ego desperto da imaginação material criativa ou produtiva, segundo as suas leis e seguindo as conveniências da linguagem. De resto, no universo dialógico ${ }^{29}$ do filósofo, e no que respeita, mais especificamente, ao "sector da palavra humana" - para seguir uma leitura de Gilbert Durand, um outro estudioso influenciado por Bachelard - a orientação é clara, a saber, orientação para o "sobreconsciente poético que se expressa por meio das palavras e das metáforas", ou seja, o sistema geral da expressão escrita e da fantasia - mais correctamente, da ficção. "Fantasia livre, escreve Durand, ou " fantasia de palavras " do leitor de poemas, pouco importa, desde que nos mantenhamos na claridade de uma consciência desperta aquém das trevas do sonho"30. A loquacidade salva a fantasia!

28 "Sans la fenêtre médiatisant l'ouverture il n'y aurait pas de monde d'image, un monde d'image sans fenêtre est en soi absurde" (id. ibid. p. 93). E mais à frente: "La "fenêtre" avec ses faces réales et irréalles est le véritable corrélat noématique de l'acte médial "conscience d'image", n'est donc pas par conséquent rien d'autre que le pur phénomène d'image lui-même".

29 A orientação dialógica do pensamento do autor encontra-se claramente expressa tanto na sua obra epistemológica como na sua obra de fenomenologia do imaginário. E ao ler Bachelard, podemos assistir a por assim dizer esse vício da terceira via, quer dizer, da ultrapassagem das dicotomias. No caso do imaginário a ultrapassagem é feita pela imaginação material, e no caso da ciência, ela é feita pela tese do racionalismo aplicado. Este último, pretenderá esclarecer o termo médio que permitiria a resolução de contra-sensos, ou da clássica dicotomia empirismo / racionalismo - a polémica intenção epistemológica bachelardiana, cujo objectivo se circunscreve a equipar o racionalismo com "provas palpáveis", e o empirismo com "leis dedutivas" (como se refere logo na Introdução da famosa La Philosophie du Non, editada em 1940 - Puf, 1988 - no mesmo ano, note-se, do seu Lautréamont).

30 Citado de um capítulo cujo tema é "As hermenêuticas instauradoras", no precioso estudo de Gilbert Durand, de 1964, A Imaginação Simbólica (Lisboa, ed. 70, 1995, p. 62 e ss.), e que, por ora, transcende o âmbito deste artigo. Mas, sobre os conceitos de Fantasia e Ficção apenas uma 
Um tópico conclusivo: só a consciência que se descobre a si mesma num papel tematizador dos seus próprios conteúdos ou teses irreais (cogito do sonhador) - de um modo geral, a tese da identidade da imagem pela imagem pode, desse modo, realizar o mundo da imagem, e conferir-lhe, assim, um valor de objecto para a análise fenomenológica dinâmica.

\section{§ 4. Conclusão}

Chegando ao termo deste esboço para uma possível interpretação fenomenológica da obra (principalmente) estética do nosso filósofo, ou se quisermos do nosso fenomenólogo, poderemos ainda afirmar que assim se compreendem algumas das dificuldades detectadas para uma interpretação rigorosa, e mais detalhada, deste fenómeno da imaginação. Por exemplo, como fazer a sua análise se sabemos, à partida, que o fenómeno da imagem reenvia constantemente a uma rede de significados co-relacionados? Esta questão centra-se numa aporia filosófica: analisar a imagem pressupõe já uma intuição do seu carácter ontológico fundamental. Circulamos pois numa hermenêutica ${ }^{31}$. A obra de arte, um reflexo, um filme, estão simplesmente, diante de nós, são apenas um ente aí lançado aos nossos olhos ou o resultado do seu ser deve-se à subjectividade?, e assim, será sempre um artefacto cultural? Eventualmente, só poderemos entender a imagem enquanto que circunscrita como malha de uma rede mais vasta de significados? Afigura-se, portanto, bastante problemática, ou insuficiente, a tentativa de isolar o puro fenómeno da imagem, de o compreender tão-só ontologicamente.

A fenomenologia busca o sentido da imaginariedade como tal. Para isso, pretende filtrar tudo o que não pertence ao, ou tudo o que prescreve o, puro fenómeno da imagem. Esta é também uma preocupação nossa, ao analisarmos a poética bachelardiana. Mas, com semelhante abstracção, não se correrá o perigo da destruição da essência do fenómeno da imagem, algo que, obviamente, não se pretende? E que sentido teria, para o sujeito, o puro fenómeno da imagem assim isolado? Estas são questões cujas respostas não preenchem as linhas orientadoras do nosso estudo. Sobre esta temática apenas uma observação: a irrealidade da imagem pura é um "ente individual concreto" 32 posto na irrealidade e não o horizonte

nota: preferimos utilizar o termo Ficção (do alemão fiktion). Este, na (nossa) perspectiva fenomenológica, é a imaginação criadora. Com efeito, o conceito de Fantasia (do alemão Fantasie), é sinónimo de imaginação simples, livre ou reprodutiva - não, certamente, o sentido que Durand pretende comunicar!...

31 A este propósito, leia-se o $\S 30$ da obra de Fink que analisamos.

32 "Il ne s'agit évidemment pas dans l'image pure d'une irréalité au sens d'une unité de signification idéale ou de la singularité idéale d'une œuvre d'art (la symphonie qui, à travers de multiples répétitions, est toujours la même) mais d'un étant individuel concret. L'interprétation noématique de la conscience d'image est une analyse de la facticité de l'image" (Fink, ob. cit. p. 88). E esta tese de Fink (autor que o próprio Husserl considerou, no prólogo a De la 
longínquo de uma significação ideal. A fenomenologia, mediante uma interpretação noemática da consciência da imagem, da imaginação reprodutiva de um objecto (por presentificação), ensina a facticidade da imagem. A imagem caracteriza-se pela sua estrutura elementar: o seu factum. E, como vimos, a imagem é "conjunto unitário homogéneo quanto ao sentido, de um suporte real e do mundo da imagem que ele transporta" ${ }^{33}$. Por exemplo, a imagem imaginada dos arquétipos, se se dá enquanto ficção, é porque em última instância se constitui por recorrência da sua facticidade.

Não se torna pois razoável admitir a existência de uma imagem à parte do mundo real da imagem, isto é, uma eídos sem suporte real. O que evita, digamos assim, uma metafísica ingénua da imagem. Na nossa perspectiva, e de acordo com o grande ensaísta da imaginação das matérias que foi Bachelard, apenas se torna razoável admitir o tradicional conceito de eídos mas no sentido homérico do termo, a saber, "aquilo que se vê". E a bem dizer, o próprio fundador da ciência fenomenológica que influenciará o nosso autor, independentemente de ter sido um simpatizante do conceito platónico de "ideia", enquanto liberta de interpretações metafísicas e dada de modo "intuitivo imediato"34 - o que levará ainda vários autores a considerá-lo, e apesar disso, como o último grande idealista do século xx - sempre fez depender, de um modo geral, toda a sua reflexão filosófica da supremacia dada ao primado da percepção, o que também se demonstra na última fase do seu pensamento, pela importância conferida à temática da Lebenswelt ${ }^{35}$.

Phénoménologie, como uma rigorosa elucidação de más compreensões) é para nós importante: abre a perspectiva para a consideração de um horizonte de impossibilidades da imaginação (hipótese desenvolvida na nossa investigação a ser brevemente editada, Bachelard e a Imaginação Material. Uma leitura fenomenológica, apresentada à F.L.U.L., em 1996).

33 "Mais l'image - telle est notre première thèse - est l'ensemble unitaire, homogène quant au sens, d'un support réal et du monde d'image qu'il porte" (Fink, ob. cit. p. 89).

34 A propósito da variação eidética escreve Husserl: “"Dieses allgemeine Wesen ist das Eidos, die» idea "im platonischen Sinn, aber rein gefasst und frei von allen metaphysischen Interpretationen; also genau so genommen, wie es in der solchem Wege entspringenden Ideenschau uns unmittelbar intuitiv zur Gegebenheit kommt" (Phänomenologische Psychologie, § 9 a), p. 73).

35 Como Jean Wahl (citado por J.-François Lyotard, La phénoménologie, PUF, 1954, 1. a parte, III, 2.) pode considerar-se, inclusive, a última fase do pensamento de Husserl, como empirista. Tal se deveria à importância conferida à temática da verdade. Não discutiremos aqui este assunto. Apenas uma observação: Husserl conceptualizou nessa expressão mundo da vida (Lebenswelt), que o sujeito é a vida, a condição sine qua non mediante a qual se (pode) recebe( $r$ ) as coisas, os dados, numa experiência actual e prévia à actividade judicativa. Pensamos, pois, que esta ideia ajuda a compreender a tese bachelardiana de que a imagem surge directa ou pré-logicamente na consciência imaginativa, dada através de uma intuição actual atenta, ou vigilante, do seu próprio ego desperto ou cogito do devaneio material. 


\section{Bibliografia}

AQUIEN, Michèle, Dictionnaire de poétique, Les Usuels de Poche, Librairie Générale Française, 1993, p. 158.

BACHELARD, Gaston, Études, recueil posthume de cinq textes présentés par G. Canguilhem, Paris, PUF, 1972.

BACHELARD, Gaston, La Poétique de la Rêverie, Paris, 3. . Ed. Quadrige/Puf, 1990.

BACHELARD, Gaston, L'Air et les Songes. Essai sur l'imagination de le mouvement, Paris, Librairie José Corti, 1943.

DUFRENNE, M., "Gaston Bachelard et la poésie de l'imagination", in Les Études Philosophiques, 4, 1963.

DURAND, G., A Imaginação Simbólica, Lisboa, ed. 70, 1995.

FINK, E., De la Phénoménologie, Tradui de l'allemand par Didier Franck, avec un avant-propos de E. Husserl, Paris, Ed. de Minuit, Arguments, 1974.

HUSSERL, Edmund, Logische Untersuchungen, V, (Husserliana XIX / 1), zweiter Band, erster Teil, Den Hague, Martinus Nijhoff, 1984.

HUSSERL, Edmund, Phänomenologische Psychologie. Vorlesungen Sommersemester 1925. Herausgegeben von W. Biemel. (Husserliana IX), zweite Auflag, Den Hague, Martinus Nijhoff, 1962.

LYOTARD, J.-François, La phénoménologie, PUF, 1954.

NOVALIS, Fragmentos, (ed. bilingue), Lisboa, Assírio e Alvim, 1992.

PAISANA, João, Fenomenologia e Hermenêutica, Lisboa, Presença, 1992.

SARAIVA, Maria Manuela, "O primado da percepção e a concepção da obra de arte em Husserl”, in Revista da Universidade de Coimbra, 1965.

SARAIVA, Maria Manuela, L'imagination selon Husserl, Martinus Nijhoff, La Haye, 1970.

SARTRE, Jean-Paul, L'imagination, Paris, PUF, 1981.

SARTRE, Jean-Paul, L'Imaginaire. Psychologie phénoménologique de l'imagination, Paris, Gallimard, Col. folio essais, 1968.

\section{Abstract}

La grille phénoménologique ordinairement, et la phénoménologie husserlienne en particulier, sont les outillages conceptuels que d'un mode général peuvent éclairer la magnifique prose bachelardienne, nommément sa pensée esthétique sur l'imagination des matières, sur la rêverie matérielle de la tétralogie des élements naturels. De même que le phénomène n'est pas au-delà de son apparaître, aussi l'image matérielle, elle même, s'épuise dans cet acte d'une évidence aprioristique, ce qui lui confère le sens propre de l'image, à savoir, l'image par l'image. L'imagination se constitue donc en tant qu'une unité de présentafication / neutralisation au dedans de la consciense esthétique. Nous pouvons distinguer la fonction thématique de l'imagination de la fonction positionelle de l'imagination et les rapporter au lieu originel d'une irrealité, d'un fictum. 